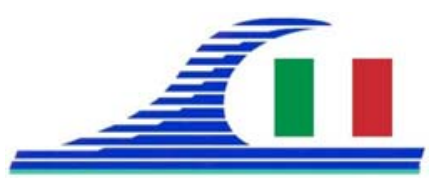

\title{
The increasing vulnerability of river deltas in the Mediterranean
}

\author{
Edward J. ANTHONY ${ }^{1}$
}

\begin{abstract}
1. Aix-Marseille Université, Institut Universitaire de France, CEREGE UM 34, Europôle de l'Arbois, Avenue Louis Philibert, 13545 Aix en Provence, France. anthony@cerege.fr
\end{abstract}

\begin{abstract}
:
River deltas are extremely important to the Mediterranean region's geography and resources, and have been for many millennia. They offer fertile soils for agriculture, freshwater resources and rich biodiversity. The nature and growth of the Mediterranean's river deltas reflect the cumulative interplay of several natural factors and the increasingly overarching influence of human activities. These factors include inherited coastal geology and coastal morphology, sea-level oscillations, a potentially complex and variable relationship between climate change, landscape degradation and fluvial sediment supply, and the oceanographic regime. The human influence has acted directly and indirectly on fluvial sediment supply and via engineered interventions on rivers and the coast. The patterns of river delta growth and delta morphodynamics in the Mediterranean, thus, reflect adaptations to pulsed sediment supply, river discharge variations, the microtidal, fetch-limited context, and human interventions.

The marked progradation dynamic that prevailed during the Roman period, influenced by human activities, and during the Little Ice Age, contrasts markedly with the situation of common destabilisation over the last two centuries, particularly well documented for the last 50 years. This period has been characterised by reduced sediment flux due to catchment reforestation, retention within reservoirs, and fluvial regulation and dredging, resulting in the erosion of deltas and adjacent barrier-lagoon and beach-dune systems. In addition to catchment destabilisation, the human presence on Mediterranean deltas is also a challenge in terms of maintaining their integrity. Many of the societal problems associated with deltaic erosion and flooding are, unfortunately, often compounded by high population densities and by the economic attractiveness of these areas for urbanisation, agriculture, transport, industry and recreational purposes. Human impacts in Mediterranean river catchments and human presence and activities within the regions' deltas have thus been driving significant changes in deltaic and adjacent systems, and today human engineering largely controls the growth and evolution of many of the Mediterranean's most important deltas (e.g. the Nile, the Rhône, the Ebro, the Po).

It has been argued that Mediterranean river deltas may be capable of coping with sealevel rise (SLR) through three self-reinforcing mechanisms as the SLR rates increase,
\end{abstract}


Côtes méditerranéennes menacées :

Risques et défis dans le contexte du changement climatique

and it has been claimed that these mechanisms would tend to enhance the efficiency of the deltaic sedimentary trap. These are: (a) an increase in the frequency of delta lobe switching with accelerated SLR leading to the formation of new lobes in shallow areas; (b) an increase in the frequency and magnitude of flood events in the delta plain as a consequence of increased crevassing through the natural river levees, leading to enhanced sediment deposition; and (c) an increase in the frequency and magnitude of overwash events in the delta fringes, enhancing the ability of sandy beaches to adapt to SLR. These considerations require, however, that the ongoing rise in sea level rise, and the sinking of deltas be more or less matched by fluvial sediment supply or by managed sediment husbandry. Although many Mediterranean deltas are largely products of human transformations of river catchments, the switch towards significant reductions in fluvial sediment supply reaching the coast today may mean that this balance is not likely to be achieved, thus probably heralding the sinking and destruction of Mediterranean deltas, but also more widespread erosion of adjacent coasts. By reducing river liquid discharge and sediment supply, human activities invariably enhance the potential influence of waves in destroying deltas. They also engender environmental vulnerability within which future rapid climate changes will operate. Two potential directions of morphological change following the weakening of river influence may be invoked for Mediterranean deltas. Those facing the dominant waves, common in the Mediterranean, may retreat while keeping their plan shape, although over time positive feedback effects may lead to a dominant drift direction. The other direction may be represented by increasingly skewed or asymmetric and finally deflected or straightened deltas as net river strength decreases over the long term whereas the wave climate is likely to become more energetic in response to climate change and greater storminess.

The move towards any form of future sustainability of the Mediterranean's deltas and adjacent clastic coasts will require a better understanding of fluvial source-to-coastal sink sediment transfers and coastal sediment budgets at various spatial and temporal scales, coastal morphodynamic processes, and the determination of shoreline change rates. These efforts will also require balancing strategies of economic development that concern not only the prosperity of high-revenue urban and/or 'strategic' shores, but also low-revenue shores that are more likely to be of ecological value. These objectives will need to be achieved within a framework that clearly identifies the stakes of the future, and that is based on concerted management strategies, especially those relating to river catchments and sediment inputs, urbanisation and coastal development.

Keywords: Mediterranean deltas, River sediment budgets, Dams, Sea-level rise, Delta sustainability, Delta destruction, Coastal destabilization 